\title{
What Causes Deep Gray Matter Atrophy in Multiple Sclerosis?
}

M ultiple sclerosis is a chronic neuroinflammatory and neurodegenerative disease of the central nervous system. Patients often experience a complex combination of physical and cognitive symptoms, both of which are strongly disabling. Unfortunately, progression of disability and cognitive decline has been difficult to understand using neuroinflammatory markers such as lesion volumes. Neurodegenerative components of MS and especially deep gray matter (DGM) atrophy continue to progress with time $^{1}$ and have a strong predictive potential for disability ${ }^{2}$ and cognitive impairment. ${ }^{3}$ Thalamic atrophy occurs very early ${ }^{4}$ and continues linearly during the disease course, ${ }^{5}$ with especially strong clinical correlations. ${ }^{6}$ Therefore, it is clear that deep gray matter and especially thalamic atrophy is of great relevance for MS, and its measurement may even become reliable enough to include in routine neuroradiologic practice. What drives this typical neurodegenerative pattern in MS, however, remains unclear, probably including a combination of network disconnection, ${ }^{7}$ Wallerian degeneration, and local damage. ${ }^{8}$

The study by Pontillo et al, ${ }^{9}$ published in the current issue of the American Journal of Neuroradiology, represents a comprehensive way to investigate the possible correlates of deep gray matter atrophy. The authors apply several MR imaging measures of diffusion, perfusion, and susceptibility in the DGM in relapsingremitting MS (RRMS, $n=52$ ) and progressive MS $(n=25)$, which were compared with those in healthy controls $(n=44)$. Results show that white matter lesion burden was the main correlate of DGM atrophy in RRMS, possibly indicating a role for Wallerian degeneration of connected fiber bundles, resulting in structural network disconnection and atrophy. In progressive MS, however, the most important correlates of atrophy were local microstructural damage and thalamic susceptibility, while lesion volumes did not strongly relate to atrophy.

These results highlight an important point, namely that the cause and consequence of atrophy could vary among the different MS phenotypes and that these should be studied separately. ${ }^{10}$ This point is supported by recent findings that while some therapeutic options that target neuroinflammation in the white matter may impact thalamic atrophy in RRMS, ${ }^{11}$ these do not impact disease progression in progressive MS. ${ }^{12}$ Nonetheless, recent studies have shown that thalamic atrophy rates are similar in all phenotypes, ${ }^{5}$ indicating that neurodegeneration continues in progressive MS even when the formation of new neuroinflammatory lesions may become less apparent. These findings could reflect an entirely different local pathologic process or may indicate a second-order disconnection effect ${ }^{10}$ induced by an accelerated cortical degeneration of important networks such as the default mode network, ${ }^{2}$ causing additional waves of disconnection leading to a so-called network collapse. ${ }^{13}$

This notion of network disconnection was also supported by a recent study using experimental autoimmune encephalomyelitis, showing inflammation and demyelination in the spinothalamic tracts to be related to thalamic neuronal loss, while lesions within the thalamus itself were scarce. ${ }^{14}$ In MS, focal lesions within DGM structures also do not seem to be that common and appear to be poorly related to DGM atrophy. ${ }^{15}$ In fact, neuronal loss in nondemyelinated DGM tissue can be as severe as 35\%. ${ }^{16}$ Other work $^{17}$ has also indicated that the DGM has a less severe neuroinflammatory profile than the white matter. However, diffuse microglial activation within the thalamus has also been noted using PET research, especially in progressive $\mathrm{MS},{ }^{18}$ which was also related to cortical thinning and clinical dysfunction, ${ }^{19}$ again indicating a network effect. It remains unclear, however, whether microglial activation is a cause of neurodegeneration or a consequence of it, or both. Susceptibilityweighted imaging as used in the present study by Pontillo et $\mathrm{al}^{9}$ has also been indicated to reflect both microglial activation (ie, through changes in iron levels) and myelin content, further complicating matters. ${ }^{20}$

As Pontillo et $\mathrm{al}^{9}$ note, future longitudinal multimodal studies are now required to disentangle the causal chain of events for these different local and network-based pathologic processes. It seems apparent, however, that the cause and consequence of DGM atrophy will remain a complex combination of primary and second-order effects. Thus, future treatment strategies aiming to impact DGM atrophy may need to impact the disease early, to prevent the network collapse from happening altogether. 


\section{REFERENCES}

1. Eshaghi A, Marinescu RV, Young AL, et al. Progression of regional grey matter atrophy in multiple sclerosis. Brain 2018;141:1665-77 CrossRef Medline

2. Eshaghi A, Prados F, Brownlee WJ, et al. Deep gray matter volume loss drives disability worsening in multiple sclerosis. Ann Neurol 2018;83:210-22 CrossRef Medline

3. Eijlers AJ, Van Geest Q, Dekker I, et al. Predicting cognitive decline in multiple sclerosis: a 5-year follow-up study. Brain 2018;141: 2605-18 CrossRef Medline

4. Zivadinov R, Havrdová E, Bergsland N, et al. Thalamic atrophy is associated with development of clinically definite multiple sclerosis. Radiology 2013;268:831-41 CrossRef Medline

5. Azevedo CJ, Cen SY, Khadka S, et al. Thalamic atrophy in multiple sclerosis: a magnetic resonance imaging marker of neurodegeneration throughout disease. Ann Neurol 2018;83:223-34 CrossRef Medline

6. Minagar A, Barnett MH, Benedict RH, et al. The thalamus and multiple sclerosis: modern views on pathologic, imaging, and clinical aspects. Neurology 2013;80:210-19 CrossRef Medline

7. Schoonheim MM, Meijer KA, Geurts JJ. Network collapse and cognitive impairment in multiple sclerosis. Front Neurol 2015;6:82 CrossRef Medline

8. Kipp M, Wagenknecht $\mathrm{N}$, Beyer $\mathrm{C}$, et al. Thalamus pathology in multiple sclerosis: from biology to clinical application. Cell Mol Life Sci 2015;72:1127-47 CrossRef Medline

9. Pontillo G, Cocozza S, Lanzillo R, et al. Determinants of deep gray matter atrophy in multiple sclerosis: a multimodal MRI study. AJNR Am J Neuroradiol 2019;40:99-106 CrossRef

10. Larochelle C, Uphaus T, Prat A, et al. Secondary progression in multiple sclerosis: neuronal exhaustion or distinct pathology? Trends Neurosci 2016;39:325-39 CrossRef Medline

11. Gaetano L, Häring DA, Radue EW, et al. Fingolimod effect on gray matter, thalamus, and white matter in patients with multiple sclerosis. Neurology 2018;90:e1324-32 CrossRef Medline

12. Ziemssen T, Derfuss T, de Stefano N, et al. Optimizing treatment success in multiple sclerosis. J Neurol 2016;263:1053-65 CrossRef Medline

13. Schoonheim MM, Meijer KA, Geurts JJ. Network collapse and cognitive impairment in multiple sclerosis. Front Neurol 2015;6:82 CrossRef Medline

14. Wagenknecht N, Becker B, Scheld M, et al. Thalamus degeneration and inflammation in two distinct multiple sclerosis animal models. J Mol Neurosci 2016;60:102-14 CrossRef Medline

15. van de Pavert SH, Muhlert N, Sethi V, et al. DIR-visible grey matter lesions and atrophy in multiple sclerosis: partners in crime? $\mathrm{J} \mathrm{Neu-}$ rol Neurosurg Psychiatry 2016;87:461-67 CrossRef Medline

16. Cifelli A, Arridge M, Jezzard P, et al. Thalamic neurodegeneration in multiple sclerosis. Ann Neurol 2002;52:650-53 CrossRef Medline

17. Vercellino M, Masera S, Lorenzatti M, et al. Demyelination, inflammation, and neurodegeneration in multiple sclerosis deep gray matter. J Neuropathol Exp Neurol 2009;68:489-502 CrossRef Medline

18. Rissanen E, Tuisku J, Vahlberg T, et al. Microglial activation, white matter tract damage, and disability in MS. Neurol Neuroimmunol Neuroinflamm 2018;5:e443 CrossRef Medline

19. Herranz E, Gianni C, Louapre C, et al. Neuroinflammatory component of gray matter pathology in multiple sclerosis. Ann Neurol 2016;80:776-90 CrossRef Medline

20. Schweser F, Raffaini Duarte Martins AL, Hagemeier J, et al. Mapping of thalamic magnetic susceptibility in multiple sclerosis indicates decreasing iron with disease duration: a proposed mechanistic relationship between inflammation and oligodendrocyte vitality. Neuroimage 2018;167:438-52 CrossRef Medline

(1) M.M. Schoonheim (D).J.G. Geurts Department of Anatomy and Neurosciences MS Center Amsterdam Amsterdam Neuroscience Amsterdam UMC, Vrije Universiteit Amsterdam Amsterdam, the Netherlands 